\title{
Pattern of lipid alterations in subclinical hypothyroidism: response to Levothyroxine replacement
}

\author{
Pala N. A. ${ }^{1}$, Ashraf M. ${ }^{2}$, Bhoughal B.N. ${ }^{3}$ \\ ${ }^{1}$ Dr Nazir Ahmad Pala, Lecturer, ${ }^{2}$ Dr Mohd Ashraf, Assistant Professor, ${ }^{3}$ Dr Badrinath Bhoughal, Associate \\ Professor. All authors are affiliated with department of Medicine, Government Medical College, Srinagar, \\ Jammu and Kashmir, India.
}

Address for Correspondence: Dr Nazir Ahmad Pala, Lecturer, Department of Medicine, Government Medical College, Srinagar, Jammu and Kashmir, India. E-mail: nazirpala2@gmail.com

\begin{abstract}
Objectives: (1) To assess the association of subclinical hypothyroidism (SCH) and lipid profile (2) To quantify the effect of thyroxine treatment on lipid profile.Methods:In a non-randomized matched design, 320 patients who were detected to have SCH and 180 euthyroid controls, matched for age and BMI (body-mass index), werestudied for lipid parameters.Subjects with $\mathrm{SCH}$ were further subdivided on the basis of their thyroid functional status: $\mathrm{SCH}$ with $\mathrm{TSH} \leq 10.0 \mathrm{mIU} / \mathrm{L}(\mathrm{SCH}-1)$ and $\mathrm{SCH}$ with $\mathrm{TSH}>10 \mathrm{mIU} / \mathrm{L}(\mathrm{SCH}-2)$. Subjects in SCH-2 group were started on thyroxine replacement and were followed up after 3 months with a repeat lipid profile. Results: Mean total cholesterol (TC) and low-density lipoprotein (LDL) levels were higher and mean high-density lipoprotein (HDL) significantly lower in SCH (SCH-1 and SCH-2) compared to euthyroid controls, but there was no statistically significant difference in the mean triglyceride (TG) levels. Subjects in SCH-2 group had significantly higher mean LDL and lower mean HDL compared to SCH-1 group. There was a significant reduction in mean TC and LDL and increase in HDL after treatment with thyroxine, while there was no significant difference among the mean TG levels. Conclusion:Subclinical hypothyroidism is associated with TSH dependent rise in TC and LDL and fall in HDL compared to controls. Achieving euthyroid status with thyroxine has a favourable effect on lipid profile
\end{abstract}

Keywords: Anti-TPO antibodies, Levothyroxine, Lipid Profile, Subclinical hypothyroidism

\section{Introduction}

Thyroid hormone plays a pivotal role in the synthesis, fate and mobilization of lipids, in addition to its role in development and differentiation of cells $[1,2]$. Lipid abnormalities are well known inpeople with overt hypothyroidism, with significant increase in plasma total cholesterol (TC), even an association of totalcholesterol and thyroid stimulating hormone (TSH) has been reported in euthyroid individuals $[3,4,5,6,7]$.

Similarly, increase in total cholesterol (TC), triglycerides (TG) and Low-density lipoprotein (LDL) has been demonstrated in people with subclinical hypothyroidism $(\mathrm{SCH})$ by various studies [8,9], although similar results were not

Manuscript received: $5^{\text {th }}$ September 2017

Reviewed: $15^{\text {th }}$ September 2017

Author Corrected: $21^{\text {st }}$ September 2017

Accepted for Publication: 26 $6^{\text {th }}$ September 2017 reproduced by others $[10,11,12]$. The beneficial effect of thyroxine replacement on total cholesterol in people with subclinical hypothyroidism isa matter of debate [13], although some expertsstill believe that subclinical hypothyroidism, even with $\mathrm{TSH} \leq 10.0 \mathrm{mIU} / \mathrm{L}$ should be treated with thyroxine because of its association with lipid abnormalities [14].

In view of conflicting data with regard to the nature and degree of lipid abnormalities in people with subclinical hypothyroidism and also the lack of clear understanding about the effect of thyroxine replacement,we designed a study to evaluate theassociation of lipid parameter sand sub clinical hypothyroidism and to estimate the effect of thyroxine replacement on these parameters. 


\section{Material and Methods}

This study was conducted in endocrine division of Department of medicine at a tertiary care hospital in north India.

Study design- This was a prospective randomised case-control observational study.

Inclusion criteria- People with newly diagnosed subclinical hypothyroidism and matched healthy controls.

Exclusion criteria- People with history of diabetes or pre-diabetes, coronary artery disease, liver disease, renal or thyroid disease on treatment, overt hypo or hyperthyroidism, alcoholism, or receiving lipid lowering agents, were excluded from the study.

Sample size- The sample size was calculated for the moderate effect size ' $d$ ' with the help of statistical software $G$ power 3.1.9.2 by taking appropriate statistical methodsfor the study under consideration. The power of the study i.e., $(1-\beta)$ is $80 \%$ and the level of significance $\alpha$ is $5 \%$.

Study subjects and datavariables- 320 people with subclinical hypothyroidism randomly selected from endocrine outpatient department and 180 controls matched for age and BMI were included in the study and informed consent was obtained from all the study subjects. After initialrecruitment, study subjects who were divided into three groups on the basis of TSH values: normal thyroid function (Control), SCH-1 (normal T4 with $\mathrm{TSH} \leq 10.0 \mathrm{mIU} / \mathrm{L}$ ) and $\mathrm{SCH}-2$ (normal T4 with $\mathrm{TSH}>10.0 \mathrm{mIU} / \mathrm{L}$ ), underwent thorough clinical, biochemical and immunological evaluation, apart from thyroid function tests, which were performed at the time of recruitment. Serum samples were processed for lipid profile and anti-thyroid peroxidase (Anti-TPO) antibodies. Subjects in $\mathrm{SCH}-2$ group were given levothyroxine replacement andre-assessment of thyroid function and lipid profile was done after 3 months of treatment. Lipid parameters were analysed with commercially available enzymatic reagents (Audit Diagnostics, Ireland) adapted to the Hitachi 912 autoanalyzer. The upper normal limit for reference population for fasting total cholesterol, LDL, HDL and TG were 5.18, 3.10, 1.8, 2.26 and 5.5mmol/1 respectively. TSH, T4 and T3 were also measured by using commercial chemiluminescent immunoassays (Beckman Coulter Unicel, DXI).

The normal range for $\mathrm{T} 3, \mathrm{~T} 4$, and $\mathrm{TSH}$ as provided by manufacturers of kits is $(0.7-2.5 \mathrm{ng} / \mathrm{ml})$, (3.5$13.59 \mu \mathrm{g} / \mathrm{dl})$, and $(0.5-6.5 \mathrm{mIU} / \mathrm{L})$ for RIA respectively. Anti-TPO Antibody was measured using ECL kits from Roche (Germany) with normal range being 0.0-60.0 IU/L. Subjects with value of $>60.0 \mathrm{IU} / \mathrm{L}$ were considered as anti-TPO antibody positive. Subjects with TSH $>10 \mu \mathrm{IU} / 1$ were put on $50 \mathrm{mcg}$ thyroxine/day and dose was titrated till TSH normalization. During the study period, subjects were instructed to consume their routine homemade diet and not to curtail physical activity and diet.

Statistical methods- The statistical software SPSS 20 was used to analyse the data. Data were presented as mean \pm SD and $n(\%)$. The Parametric and non-parametric tests have been used to analyse the data after verifying the distribution of variables with the help of Shapiro- Wilk test. The Student's independent $\mathrm{t}$ test and Wilcoxon-Mann-Whitney $\mathrm{U}$ test was used to compare the parameters between cases and controls at baseline. Also the paired t test and Wilcoxon signed rank test has been used to analyze the data at baseline and at 3 months after thyroxine treatment. Pearson's correlation was calculated to assess the strength of relationship between thyroid function test and lipid parameters. All results have been described on $5 \%$ level of significance i.e. $P$ value of $<\mathbf{0 . 0 5}$ being considered as significant.

\section{Results}

Thyroidal status and lipid parameters of cases and controls- Baseline hormonal and lipid parameters of 500 subjects (320 cases and 180) controls is shown in [table1]. Meanage (years) of controls was comparable to those of SCH-1 (33.76 \pm 9.62 vs $33.85 \pm 10.54, P=0.50$ and $\mathrm{SCH}-2$ group $(33.76 \pm 9.6233$ vs $48 \pm 9.62, P=0.72)$. Although, no lipid abnormalities were seen in people with SCH-1 or SCH-2, comparedto age and BMI matched controls. However, in SCH-1 group, serum total cholesterol (4.22 \pm 0.46 vs $4.19 \pm 0.41 \mathrm{mmol} / \mathrm{l}, P=0.002)$ and LDL $(2.02 \pm 0.20$ vs $1.97 \pm 0.19 \mathrm{mmol} / \mathrm{l}, P=0.003)$ were significantly higher compared to controls. Serum HDL 
$(0.84 \pm 0.05$ vs $0.85 \pm 0.04 \mathrm{mmol} / 1, P=0.006)$ was significantly lower, TG $(1.23 \pm 0.43$ vs $1.17 \pm 0.33, P=0.08)$ was lower, however it was not statistically significant. Similarly, TC $(4.26 \pm 0.05$ vs $4.19 \pm 0.41 \mathrm{mmol} / 1, P=0.003)$, LDL $(2.03 \pm 0.20$ vs $1.97 \pm 0.19, P=0.001)$ was significantly higher and HDL $(0.83 \pm 0.05$ vs $0.85 \pm 0.04, P=<$ $0.0001)$ was lower in SCH-2 group as compared to controls. TG(1.22 \pm 0.33 vs $1.17 \pm 0.33, P=0.08)$ was higher but did not achieve statistical significance. While comparing the lipid parameters of SCH-1 with that of SCH-2 group, it was evident that subjects in SCH-2 group had significantly higher LDL $(2.03 \pm 0.20$ vs $2.02 \pm 0.20$ $\mathrm{mmol} / \mathrm{l}, P=0.001)$ and lower HDL $(0.83 \pm 0.05$ vs $0.84 \pm 0.05 \mathrm{mmol} / 1, P=<0.0001)$ compared to SCH- 1 group. However, there was no significant difference in TC $(4.26 \pm 0.05$ vs $4.22 \pm 0.46 \mathrm{mmol} / \mathrm{l}, P=0.25)$ and $\mathrm{TG}$ $(1.22 \pm 0.33$ vs $1.23 \pm 0.43 \mathrm{mmol} / \mathrm{l}, P=0.41)$ while comparing two groups.

Table-1: Baseline Characteristics of study population.

\begin{tabular}{|c|c|c|c|c|}
\hline Parameter & Controls & SCH-1 & SCH-2 & Pvalue \\
\hline Number(n) & 180 & 160 & 160 & \\
\hline Age(years) & $33.76 \pm 9.62$ & $33.85 \pm 10.54$ & $33.48 \pm 9.62$ & $0.50 * 0.72 \dagger \quad 0.65 \ddagger$ \\
\hline $\mathrm{BMI}(\mathrm{kg} / \mathrm{m} 2)$ & $24.13 \pm 0.20$ & $24.23 \pm 0.25$ & $23.33 \pm 0.37$ & $0.22 * 0.58 \dagger \quad 0.80 \ddagger$ \\
\hline Gender ratio (M\%: F \%) & $49.44 / 50.55$ & $52.5 / 47.5$ & $50.6 / 49.4$ & \\
\hline Cholesterol(mmol/l) & $4.19 \pm 0.41$ & $4.22 \pm 0.46$ & $4.26 \pm 0.05$ & $0.002 * 0.003 \dagger 0.25 \ddagger$ \\
\hline Triglycerides $(\mathrm{mmol} / \mathrm{l})$ & $1.17 \pm 0.33$ & $1.23 \pm 0.43$ & $1.22 \pm 0.33$ & $0.081 * 0.083 \dagger 0.41 \ddagger$ \\
\hline $\mathrm{LDL}(\mathrm{mmol} / \mathrm{l})$ & $1.97 \pm 0.19$ & $2.02 \pm 0.20$ & $2.03 \pm 0.20$ & $0.003 * 0.001 \dagger 0.001 \ddagger$ \\
\hline $\mathrm{HDL}(\mathrm{mmol} / \mathrm{l})$ & $0.85 \pm 0.04$ & $0.84 \pm 0.05$ & $0.83 \pm 0.05$ & $0.006 *<0.0001 \dagger<0.0001 \dagger$ \\
\hline $\mathrm{TSH}(\mu \mathrm{IU} / \mathrm{L})$ & $3.29 \pm 1.10$ & $11.01 \pm 0.65$ & $8.29 \pm 0.87$ & $<0.0001 *<0.0001 \uparrow<0.0001 \ddagger$ \\
\hline $\mathrm{T} 4(\mu \mathrm{g} / \mathrm{dl})$ & $9.70 \pm 1.33$ & $9.68 \pm 1.28$ & $9.72 \pm 1.23$ & $\begin{array}{lll}0.14 * & 0.14 \dagger & 0.001 \ddagger\end{array}$ \\
\hline $\mathrm{T} 3(\mathrm{ng} / \mathrm{ml})$ & $1.88 \pm 0.26$ & $1.86 \pm 0.23$ & $1.82 \pm 0.23$ & $0.05^{*}<0.0001 \uparrow<0.0001 \ddagger$ \\
\hline
\end{tabular}

Data expressed as mean $\pm \mathrm{SD} * P$ value between control group and $\mathrm{SCH}-1$ group, $\uparrow P$ value between control group and $\mathrm{SCH}-2$ group, $\ddagger P$ value between $\mathrm{SCH}-1$ and $\mathrm{SCH}-2$ group.

Mean TSH of euthyroid subjects was significantly lower than that of people in SCH-1 and SCH-2 group (3.29 \pm 1.10 vs8.29 $\pm 0.87 \mu \mathrm{IU} / \mathrm{L}, P-<0.0001$ and3.29 \pm 1.10 vs $11.01 \pm 0.65 \mu \mathrm{IU} / \mathrm{L}, P=<0.0001$ respectively). Mean $\mathrm{T} 4$ of euthyroid subjects was comparable to that $\mathrm{SCH}-1$ and $\mathrm{SCH}-2$ group(9.70 $\pm 1.33 \mathrm{vs} 9.68 \pm 1.28 \mu \mathrm{g} / \mathrm{dl}, P=0.14$ and $9.70 \pm 1.33$ vs $9.72 \pm 1.23 \mu \mathrm{g} / \mathrm{dl}, P=0.14$ respectively) while that of $\mathrm{SCH}-2$ group was significantly lower than $\mathrm{SCH}-1(9.68 \pm 1.28 \mathrm{vs} 9.72 \pm 1.23 \mu \mathrm{g} / \mathrm{dl}, P=0.001)$. Mean serum T3 in $\mathrm{SCH}-2$ group was significantly lower than that of euthyroid controls $(1.82 \pm 0.23$ vs $1.82 \pm 0.23 \mathrm{ng} / \mathrm{ml}, P=<0.0001)$ and $\mathrm{SCH}-1$ group $(1.82 \pm 0.23 \mathrm{vs}$ $1.86 \pm 0.23 \mathrm{ng} / \mathrm{ml}, P=<0.0001$ ).Similarly, mean serum T3 in SCH-1 group was lower than euthyroid controls $(1.86 \pm 0.23$ vs $1.88 \pm 0.26 \mathrm{ng} / \mathrm{ml}, P=0.05)$.

To remove the confounding effect of SCH status, we compared euthyroid controls with anti-TPO positivity with those who were anti-TPO negative, in the same group, Anti-TPO positive subjects had significantly higher levels of TC $(4.23 \pm 0.34$ vs $4.21 \pm 0.33 \mathrm{mmol} / \mathrm{l}, P=0.01)$ and $\operatorname{LDL}(2.0 \pm 0.2$ vs $1.97 \pm 0.18, P=0.02)$ with comparable HDL and TG levels.

Table- 2: Comparison of lipids between controls and SCH-2 before and after thyroxine replacement

\begin{tabular}{|c|c|c|c|c|}
\hline Parameter & Controls & $\begin{array}{c}\text { SCH-2 pre } \\
\text { treatment }\end{array}$ & $\begin{array}{c}\text { SCH-2 post- } \\
\text { treatment }\end{array}$ & P value \\
\hline Cholesterol(mmol/l) & $4.19 \pm 0.41$ & $4.26 \pm 0.05$ & $4.13 \pm 0.26$ & $0.003^{*} 0.12 \dagger$ \\
\hline Triglycerides $(\mathrm{mmol} / \mathrm{l})$ & $1.17 \pm 0.33$ & $1.22 \pm 0.33$ & $1.14 \pm 0.28$ & $0.083^{*} 0.32 \dagger$ \\
\hline $\mathrm{LDL}(\mathrm{mmol} / \mathrm{l})$ & $1.97 \pm 0.19$ & $2.03 \pm 0.20$ & $1.97 \pm 0.16$ & $0.001^{*} 0.98 \dagger$ \\
\hline HDL $(\mathrm{mmol} / \mathrm{l})$ & $0.85 \pm 0.04$ & $0.83 \pm 0.05$ & $0.85 \pm 0.05$ & $<0.0001^{*} 0.29 \dagger$ \\
\hline
\end{tabular}

Data expressed as mean $\pm \mathrm{SD} * P$ value between $\mathrm{SCH}-2$ pre and post-treatment, $\dagger P$ value between control group and $\mathrm{SCH}-2$ post-treatment. 
Lipid profile of SCH-2 group before and after thyroxine replacement- We analysed the effect of thyroxine replacement on lipid profile in SCH-2 group. Subjects in SCH-2 group post-treatment, had significantly lower levels of TC ( $4.13 \pm 0.26$ vs $4.26 \pm 0.05 \mathrm{mmol} / 1, P=0.003)$, LDL $(1.97 \pm 0.16$ vs $2.03 \pm 0.20 \mathrm{mmol} / 1, P=0.001)$ and higher levels of HDL $(0.85 \pm 0.05$ vs $0.83 \pm 0.05 \mathrm{mmol} / 1, P=<0.0001)$ compared to SCH-2 group pre-treatment. Similarly, SCH-2 group post-treatment had lower levels of TG $(1.14 \pm 0.28$ vs $1.22 \pm 0.33 \mathrm{mmol} / \mathrm{l}, P=0.08)$ compared to pre-treatment levels, however it did not achieve a statistical significance. Serum TC, LDL, TG and HDL of SCH-2 group post-treatment were comparable to euthyroid healthy controls [Table 2].

\section{Discussion}

Thyroid hormone has a great impact on lipid metabolism, as it is needed for the catabolism and synthesis of lipids and its deficiency may create alteration in lipid metabolism probably as a result of its predominant effect on degradation of lipids [1].

Effect of subclinical hypothyroidism on lipidsAlthough, many studies have demonstrated the nature and degree of dyslipidemia in overt hypothyroidism and there is little doubt about the beneficial effects of thyroxine replacement on serum lipids and on the risk for coronary artery disease $[15,16]$, the study results with regard to the relationship between serum lipids, cardiovascular disease and subclinical hypothyroidism have been inconsistent. In a cross-sectional outpatient study, TC and LDL-C were clearly elevated in people with overt hypothyroidism, but there were no significant differences in serum total cholesterol, LDL-C, HDL-C, or triglyceride levels between people with subclinical hypothyroidism and the euthyroid control group [17]. Similarly, subclinical hypothyroidism was not found to beassociated with alterations in total cholesterol, LDL-C, triglycerides, or HDL-Cin an age, gender and race adjusted community based health survey, as also reported by a cross-sectional study from Japan $[18,19]$. In contrast, fasting total cholesterol and LDL-C levels were significantly greater in individuals with diminished thyroid function, with higher levels in people with subclinical hypothyroidism than in euthyroid subjects in landmark Colorado case-control study [20], which is consistent with the results in the present study.

The possible reason for dyslipidemia in people with subclinical hypothyroidism could be the decrease in LDL cell surface receptors or their decreased activity, leading to increase in plasma LDL and total cholesterol. Although, there is no consistent effect of subclinical hypothyroidism on overall HDL-C serum concentrations, thyroid hormone does appear to play a role in determining the size and density of HDL-C particles. In our study, people with subclinical hypothyroidism had significantly lower levels of HDL compared to age, gender and BMI matched controls, and similar results were shown by others [21]. In our study, serum TG in euthyroid controls was lower than people with subclinical hypothyroidism, however, it did not achieve statistical significance The impact of change in the severity of subclinical hypothyroidism on lipids has been inconsistent. Higher dyslipidemic changes (atherogenic lipid abnormalities) have been observed in adult men and women with $\mathrm{TSH}>10 \mu \mathrm{IU} / \mathrm{L}$ compared to those having $\mathrm{TSH} \leq 10 \mu \mathrm{IU} / \mathrm{L}$ in various observational studies [22, 23]. In our study, we also demonstrated significantly higher levels of LDL cholesterol in SCH-2 group (TSH $>10 \mu \mathrm{IU} / \mathrm{L}$ ) compared to those in $\mathrm{SCH}-1$ group $(\mathrm{TSH}<10 \mu \mathrm{IU} / \mathrm{L})$ However, there was no statistical difference in TC and TG between the two groups, as has been reported previously [24]. In our study, TSH was correlated positively with TC and LDL and negatively with HDL, T4 and $\mathrm{T} 3$ correlated negatively with $\mathrm{TC}$ in euthyroid controls, as has been reported previously [25]. In people with SCH, TSH was correlated positively with LDL and negatively with HDL while as T3 was correlated positively with HDL, as revealed by previous studies in people with subclinical hypothyroidism and euthyroid subjects $[6,26]$. We could not demonstrate any relationship between thyroid status and TG

Significant alteration of lipids has been noted with autoimmune diseases [27]. Some studies have shown association between increase in TC, TG, lipoproteins and thyroid autoimmunity, while others did not find any association between these two [28,29]. In the present study, euthyroid controls with anti-TPO positivity had significantly higher levels of TC and LDL compared to those who were anti-TPO negative with comparable HDL and TG levels. 
Effect of thyroxine substitution on lipid parameters- The lipid lowering effect of thyroxine in patients with subclinical hypothyroidism is not yet established. Multiple interventional studies have evaluated the effects of L-T4 treatment on lipid profiles in patients with subclinical hypothyroidism, with mixed results.

In a randomized study, patients with subclinical hypothyroidism were randomized to no treatment $v s$. treatment with simvastatin $v s$. treatment with thyroxine. The simvastatin treated, but not the thyroxine treated patients had significant reductions in LDL-C, total cholesterol, and triglycerides [30], similar to results shown by a Cochrane review of thyroid hormone replacement in subclinical hypothyroidism [31].

Meta-analysis of 13 studies in people with subclinical hypothyroidism, on thyroxine substitution, showed marked decrease in total cholesterol independent of initial plasma levels; however, plasma levels remained elevated in most patients [32]. Others showed a significant reduction of TC and LDL without a change in TG and HDL levels [33, 34]. In our study, people in SCH-2 group (TSH $>10 \mu \mathrm{IU} / \mathrm{L}$ ), after thyroxine substitution had significantly lower levels of TC and LDL, higher HDL compared to pre-treatment levels.

TG level was lower than the pre-treatment level without a statistical significance. Lipid levels in post-treatment SCH-2 group were comparable to euthyroid controls, as has been reported previously [35]. Similar findings were revealed by Caraccio et al. in a randomized case-control study in people with subclinical hypothyroidism [36].

The variable alterations in the lipids depend on multiple factors such as age, gender, ethnicity, pretreatment lipid values, etc. Even small reductions in levels of $\mathrm{T}$. cholesterol, $\mathrm{LDL}-\mathrm{C}$, and triglyceride levels result in substantial reductions in cardiovascular morbidity

\section{Conclusion}

The findings of this study impress the fact that people with SCH have significantly higher levels of atherogenic lipids compared to matched healthy subjects, which may point to increased relative cardiovascular risk. Furthermore, people with TSH $>10 \mathrm{mIU} / \mathrm{L}$ have relatively higher risk of atherogenic lipid profile compared to those with $\mathrm{TSH} \leq 10.0 \mathrm{mIU} / \mathrm{L}$ implying that severity of rising $\mathrm{TSH}$ correlates with dyslipidemia in SCH. The improvement in lipid parameters with thyroxine replacement in people with $\mathrm{TSH}>10 \mathrm{mIU} / \mathrm{L}$ in our study, may result in substantial cardiovascular risk reduction.

Thus, our study results imply a significant link between SCH and lipids, significant lipid lowering effect of thyroxine which may translate into substantial cardiovascular risk reduction. Therefore, we recommend thyroxine replacement even in people with $\mathrm{TSH} \leq 10.0 \mathrm{mIU} / \mathrm{L}$ on individual basis. More number of studies with larger cohort of people need be conducted to establish a link between subclinical hypothyroidism, lipid parameters and cardiovascular risk.

Conflict of interest- The authors have nothing to declare

Authors' contributions- The project idea was conceived by Nazir Ahmad Pala, who also drafted the manuscript. Data was collected by Mohd Ashraf Gojri and Badrinath Bougal. Statistical Analysis was done by Nazir Ahmad Pala. All coauthors contributed to the manuscript and gave valuable suggestions for final drafting of manuscript. All authors read and approved the final manuscript.

\section{Funding: Nil, Conflict of interest: None Permission of IRB: Yes}

\section{References}

1. Yen PM. Physiological and molecular basis of thyroid hormone action. Physiol Rev. 2001 Jul;81 (3): 1097-142.

2. Pucci E, Chiovato L, Pinchera A. Thyroid and lipid metabolism. Int $\mathbf{J}$ Obes Relat Metab Disord. 2000 Jun;24 Suppl 2:S109-12.

3. Maratou E, Hadjidakis DJ, Kollias A, Tsegka K, Peppa M, Alevizaki M, Mitrou P, Lambadiari V, Boutati E, Nikzas D, Tountas N, Economopoulos T, Raptis SA, Dimitriadis G. Studies of insulin resistance in patients with clinical and subclinical hypothyroidism. Eur J Endocrinol. 2009 May;160 (5): 785 -90. doi: 10. 1530/ EJE-08-0797. Epub 2009 Jan13. 
4. Jung $\mathrm{CH}$, Sung $\mathrm{KC}$, Shin HS. Thyroid dysfunction and their relation to cardiovascular risk factors such as lipid profile, hsCRP, and waist hip ratio in Korea. Korean J Intern Med 2003 Sep; 18 (3):146-53.

5. Garduño-Garcia Jde J, Alvirde-Garcia U, LópezCarrasco G, Padilla Mendoza ME, Mehta R, Arellano-Campos O, Choza R, Sauque L, GaraySevilla ME, Malacara JM, Gomez-Perez FJ, Aguilar-Salinas CA. TSH and freethyroxine concentrations are associated with differing metabolic markers in euthyroidsubjects. Eur $\mathrm{J}$ Endocrinol. 2010 Aug;163(2):273-8. doi: 10.1530/ EJE-10-0312. Epub2010Jun1.

6. Park HT, Cho GJ, Ahn KH, Shin JH, Hong SC, Kim T, Hur JY, Kim YT, Lee KW, Kim SH. Thyroid stimulating hormone is associated with metabolic syndrome in euthyroid postmenopausal women. Maturitas. 2009 Mar 20;62(3):301-5. doi: 10.1016/j. maturitas. 2009. 01.007. Epub 2009 Feb 27.

7.Asvold BO, Vatten LJ, Nilsen TI, Bjøro T. The association between TSH within the reference range and serumlipidconcentrationsin apopulationbasedstudy. The HUNTStudy. Eur J Endocrinol. 2007 Feb;156(2):181-6.

8. Laway BA, War FA, Shah S, Misgar RA, Kumar Kotwal S. Alteration of lipidparameters in patients with sub clinicalhy pothyroidism. Int $\mathrm{J}$ Endocrinol Metab. 2014 Jul 1;12(3): e17496. doi: 10. 5812 /ijem. 17496. E Collection 2014 Jul.

9. Pirich C, Müllner M, Sinzinger H. Prevalence and relevance of thyroid dysfunction in 1922 cholesterol screening participants. J Clin Epidemiol. 2000 Jun;53(6):623-9.

10. Hueston WJ, Pearson WS. Subclinical hypothyroidism and the risk of hyper cholesterolemia. Ann Fam Med. 2004 Jul-Aug; 2 (4):351-5.

11. Biondi B, Klein I. Hypothyroidism as a risk factor for cardiovascular disease. Endocrine. 2004 Jun; 24(1):1-13.
12. Zhao M, Yang T, Chen L, Tang X, Guan Q, Zhang B, et al. Subclinical hypothyroidism might worsen the effects of aging on serum lipid profiles: A population-based case-control study. Thyroid 2015 May; 25(5):485-93. https://doi.org/ 10.1089/ thy.2014.0219.

13. Villar HC, Saconato H, Valente O. Thyroid hormone replacement for subclinical hypothyroidism. Cochrane Database Syst Rev 2009; 3: CD003419.

14. Biondi B, Cooper DS. The clinical significance of subclinical thyroid dysfunction. Endocr Rev. 2008 Feb;29(1):76-131.Epub2007 Nov 8.

15. Gillett M. Subclinical Hypothyroidism: Subclinical Thyroid Disease: Scientific Review and Guidelines for Diagnosis and Management. The Clin Biochem Rev. 2004 ; 25:191-194.

16. Shekhar R, Chowdary NVS, Das MC, Vidya D, Prabodh. Prevalence of subclinical hypothyroidism in costal region of Andhra Pradesh. S. Biomed Res. 2011;22:471-474.

17. Vierhapper H, Nardi A, Grösser P, Raber W, Gessl A. Low-density lipoprotein cholesterol in subclinicalhypothyroidism.

Thyroid.2000Nov;10(11):981-4.

18. Hueston WJ, Pearson WS. Subclinical hypothyroidism and the risk of hypercholesterolemia. Ann Fam Med. 2004 Jul-Aug;2(4):351-5.

19. Takashima N, Niwa Y, Mannami T, Tomoike $\mathrm{H}$, Iwai $\mathrm{N}$. Characterization of subclinical thyroiddys function from cardiovascular and metabolic view points: the Suitastudy. Circ J. 2007 Feb;71(2):191-5.

20. Canaris GJ, Manowitz NR, Mayor G, Ridgway EC. The Colorado thyroid disease prevalence study. Arch Intern Med. 2000 Feb 28;160(4): 526-34.

21. Pradeep S, Dibyaratna P, Sapna G , Geeta S, Pathak,MS. Indian Journal of Basic \& Applied Medical Research; June 2013; Issue-7, Vol.-2, P. 779-788. 
22. Dubey TN, Vibhor U, Deopujari K. Correlation of Subclinical Hypothyroidism with Dyslipidemia in Perimenopausal Women. International Journal of Contemporary Medical Research 2016;3(7):19281931.

23. Marwaha RK, Tandon N, Garg MK, Kanwar R, Sastry A, Narang A, Arora S, Bhadra K. Dyslipidemia in subclinical hypothyroidism in an Indian population. Clin Biochem. 2011 Oct;44(1415):1214-7. doi: 10.1016/j.clinbiochem. 2011.07. 003. Epub 2011 Jul 19.

24. Kuldip Singh, Saranpal Singh. Alteration in lipid fractions in subclinical Hypothyroidism in North Indian population.Indian J Fundam Appl Life Sci 2011;1(2):127-32.

25. Roos A, Bakker SJ, Links TP, Gans RO, Wolffenbuttel BH. Thyroid function is associated with components of the metabolic syndrome in euthyroid subjects. J Clin Endocrinol Metab. 2007 Feb;92(2):491-6. Epub 2006 Nov 7.

26. Asvold BO, Vatten LJ, Nilsen TI, Bjøro T. The association between TSH within the reference range and serumlipidconcentrationsin apopulationbasedstudy. The HUNTStudy. Eur J Endocrinol. 2007 Feb;156(2):181-6.

27. Borba EF, Carvalho JF, Bonfá E. Mechanisms of dyslipoproteinemias in systemic lupus erythematosus. Clin Dev Immunol. 2006 Jun-Dec; 13 (24): 203-8.

28. Efstathiadou Z, Bitsis S, Milionis HJ, Kukuvitis A, Bairaktari ET, Elisaf MS, Tsatsoulis A. Lipid profile in subclinical hypothyroidism: is Lthyroxine substitution beneficial? Eur J Endocrinol. 2001 Dec;145(6):705-10.

29. Michalopoulou G, Alevizaki M, Piperingos G, Mitsibounas D, Mantzos E, Adamopoulos P, Koutras DA. High serum cholesterol levels in persons with 'high-normal' TSH levels: should one extend the definition of subclinicalhypothyroidism? Eur J Endocrinol. 1998 Feb;138(2):141-5.

30. Duman D, Sahin S, Esertas K, Demirtunc R. Simvastatin improves endothelial function in patents with subclinical hypothyroidism. Heart Vessels 2007;22:88-93.

31. Villar HC, Saconato H, Valente O, Atallah AN. Thyroid hormone replacement for subclinical hypothyroidism. Cochrane Database Syst Rev. 2007 Jul 18;(3):CD003419.

32. Tanis BC, Westendorp GJ, Smelt HM. Effect of thyroid substitution on hypercholesterolaemia in patients with subclinical hypothyroidism: a reanalysis of intervention studies. Clin Endocrinol (Oxf). 1996 Jun;44(6):643-9.

33. Danese MD, Ladenson PW, Meinert CL, Powe NR. Clinical review 115: effect of thyroxine therapy on serum lipoproteins in patients with mild thyroid failure: a quantitative review of the literature. J Clin Endocrinol Metab. 2000 Sep;85 (9): 2993-3001.

34. Razvi S, Ingoe L, Keeka G, Oates C, McMillan $\mathrm{C}$, Weaver JU. The beneficial effect of L-thyroxine on cardiovascular risk factors, endothelial function, and quality of life in subclinical hypothyroidism: randomized, crossover trial. J Clin Endocrinol Metab.2007 May;92(5):1715-23.Epub 2007Feb 13.

35. Adrees M, Gibney J, El-Saeity N, Boran G. Effects of 18 months of L-T4 replacement in women with subclinical hypothyroidism. Clin Endocrinol (Oxf). 2009 Aug;71(2):298-303. doi: 10.1111/j. 1365-2265. 2008. 03509.x. Epub 2008 Dec 15 .

36. Caraccio N, Ferrannini E, Monzani F. Lipoprotein profile in subclinical hypothyroidism: response to levothyroxine replacement, a randomized placebo-controlled study. J Clin Endocrinol Metab. 2002 Apr;87(4):1533-8.

\section{How to cite this article?}

Pala N. A, Ashraf M, Bhoughal B.N. Pattern of lipid alterations in subclinical hypothyroidism: response to Levothyroxine replacement. Int J Med Res Rev 2017;5(09):865-871.doi:10.17511/ijmrr. 2017.i09.06. 